\title{
Retinopatia associada ao uso de didanosina
}

\author{
Retinopathy associated with the use of didanosine
}

\author{
Acácio Muralfia ${ }^{1}$ \\ Márcio L. Reisner ${ }^{2}$ \\ André L. L. Curi ${ }^{3}$
}

\section{RESUMO}

Os autores descrevem um caso de paciente adulto infectado com o vírus da imunodeficiência humana (HIV) que apresentou retinopatia tóxica secundária ao uso da didanosina (DDI). A didanosina é inibidor da transcriptase reversa utilizado no tratamento da síndrome da imunodeficiência adquirida(AIDS). A associação da didanosina com retinopatia é bem estabelecida em crianças, porém é bastante rara em adultos.

Descritores: Doenças retinianas/etiologia; Doenças retinianas/fisiopatologia; Síndrome da imunodeficiência adquirida; Infecções por HIV; Didanosina/efeitos adversos

\section{INTRODUÇÃO}

Desde o surgimento da síndrome da imunodeficiência adquirida (AIDS) descrita em 1981 inúmeros medicamentos vem sendo desenvolvidos a fim de combater de forma eficaz o vírus da imunodeficiência humana (HIV). Atualmente dispomos de três classes de anti-retrovirais específicos: inibidores da transcriptase reversa (nucleosídeos), inibidores da transcriptase reversa (não nucleosídeos) e inibidores da protease, que podem ser usados isoladamente ou associados. A associação de dois inibidores de transcriptase com um inibidor de protease, popularmente conhecida como coquetel, é a chamada HAART (Highly Active Anti-retroviral Therapy).

A didanosina ou DDI é um análogo da purina com atividade antiretroviral contra os vírus HIV-1 e HIV-2 incluindo as cepas resistentes à zidovudina (AZT). Intracelularmente é convertida pela enzima 5-nucleotidase em dd-IMP (dideoxytinosina 5 monofosfato) que por fim é metabolizada em sua forma ativa dd-ATP (2-3 dideoxyadenosina trifosfato), funcionando como um competidor do substrato dATP da enzima transcriptase reversa viral (inibidor competitivo) ${ }^{(1)}$.

A neuropatia periférica e a pancreatite são considerados os principais efeitos colaterais dose dependentes da didanosina, ocorrendo geralmente nos primeiros 3 a 6 meses de uso ${ }^{(1)}$. Casos de retinopatia tóxica em crianças HIV positivas são relatados associados ao uso de altas doses de DDI, porém raros casos são relatados em adultos ${ }^{(2-3)}$. O objetivo deste trabalho é descrever um caso incomum de retinopatia tóxica secundária ao uso da didanosina em adulto HIV positivo.

${ }^{1}$ Oftalmologista do Departamento de Retina e Vítreo da Oftalmoclínica Méier e Hospital de Olhos de Niterói.

${ }^{2}$ Residente do $2^{\circ}$ ano do Serviço de Oftalmologia da Universidade Federal Fluminense.

${ }^{3}$ Assistente voluntário do Serviço de Oftalmologia da Universidade Federal Fluminense - UFF (Serviço Prof. Dr. Renato Curi).

Endereço para correspondência: R. Lucidio Lago, 210 - Rio de Janeiro (RJ) CEP 20780-020. E-mail: oftalmomeier@aol.com

\section{RELATO DO CASO}

C.S., 32 anos, feminina, caucasiana, natural do Rio de Janeiro, HIV positiva há 6 anos, assintomática, compareceu ao serviço de Oftalmologia para exame oftalmológico de rotina. Apresentava contagem de CD4+ 140 
céls $/ \mathrm{mm}^{3}$ e carga viral indetectável, classificada no estágio A2 pelo CDC (Center of Disease Control 1992). A paciente estava em uso de zidovudina (AZT) e didanosina (DDI) há três anos.

Ao exame oftalmológico apresentava acuidade visual igual a 1,0 e pressão intra-ocular de $13 \mathrm{mmHg}$ em ambos os olhos. À biomicroscopia não evidenciamos alterações no segmento anterior. À fundoscopia observamos lesões numulares de coloração amarelada em forma de cinturão $360^{\circ}$ na região equatorial de ambos os olhos. Realizamos angiografia fluoresceínica que demonstrou a presença de alterações pigmentadas numulares com múltiplas áreas de atrofia do epitélio pigmentário retiniano circunscritas por áreas de hipopigmentação localizadas na região equatorial (Figuras 1, 2, 3,4). Havia também uma discreta diminuição da vascularização periférica.

A paciente apresentava hemograma normal, Rx de tórax sem alterações, VDRL negativo, sorologia para toxoplasmose negativa e IgG para CMV positivo. Consideramos as lesões apresentadas pela paciente como sendo secundárias ao uso da didanosina.

\section{DISCUSSÃO}

Várias são as doenças oportunistas que afetam os olhos
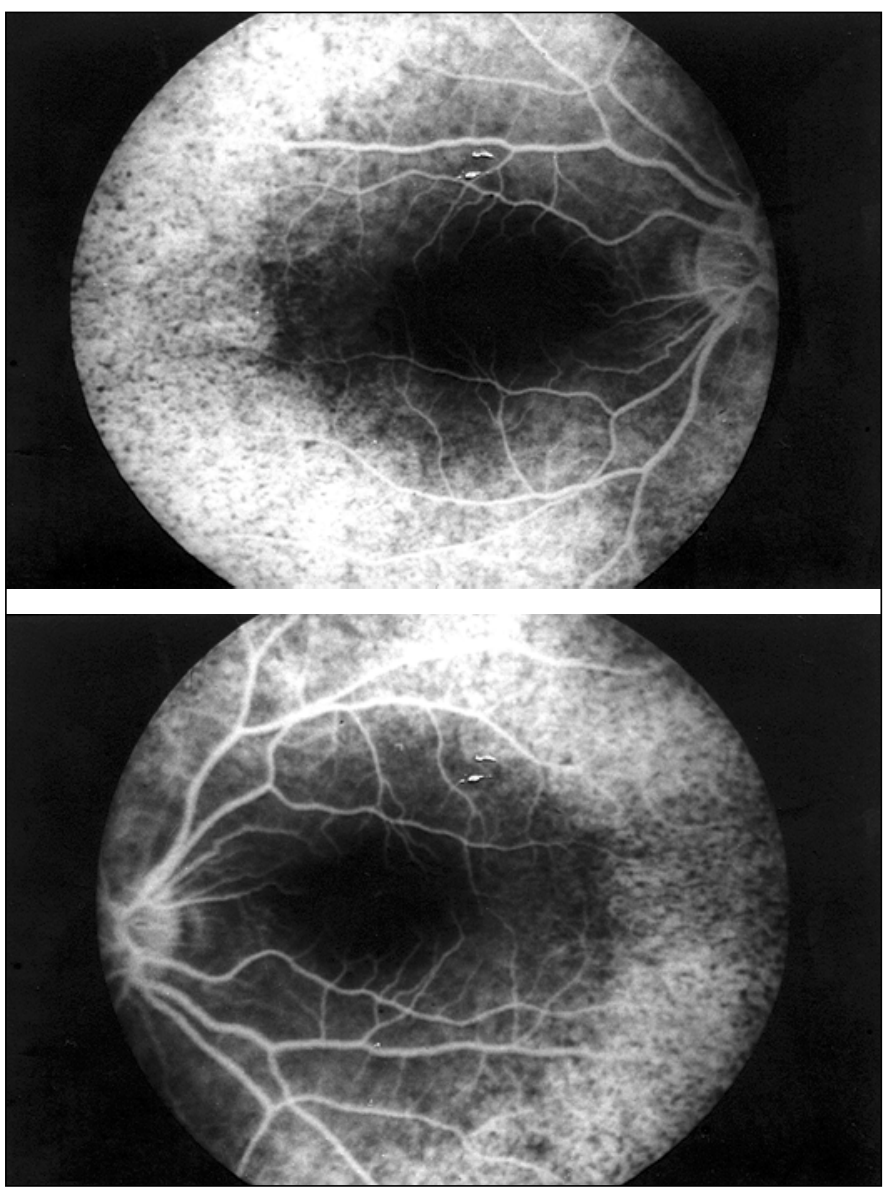

Figuras 1 e 2 - Angiografia do polo posterior
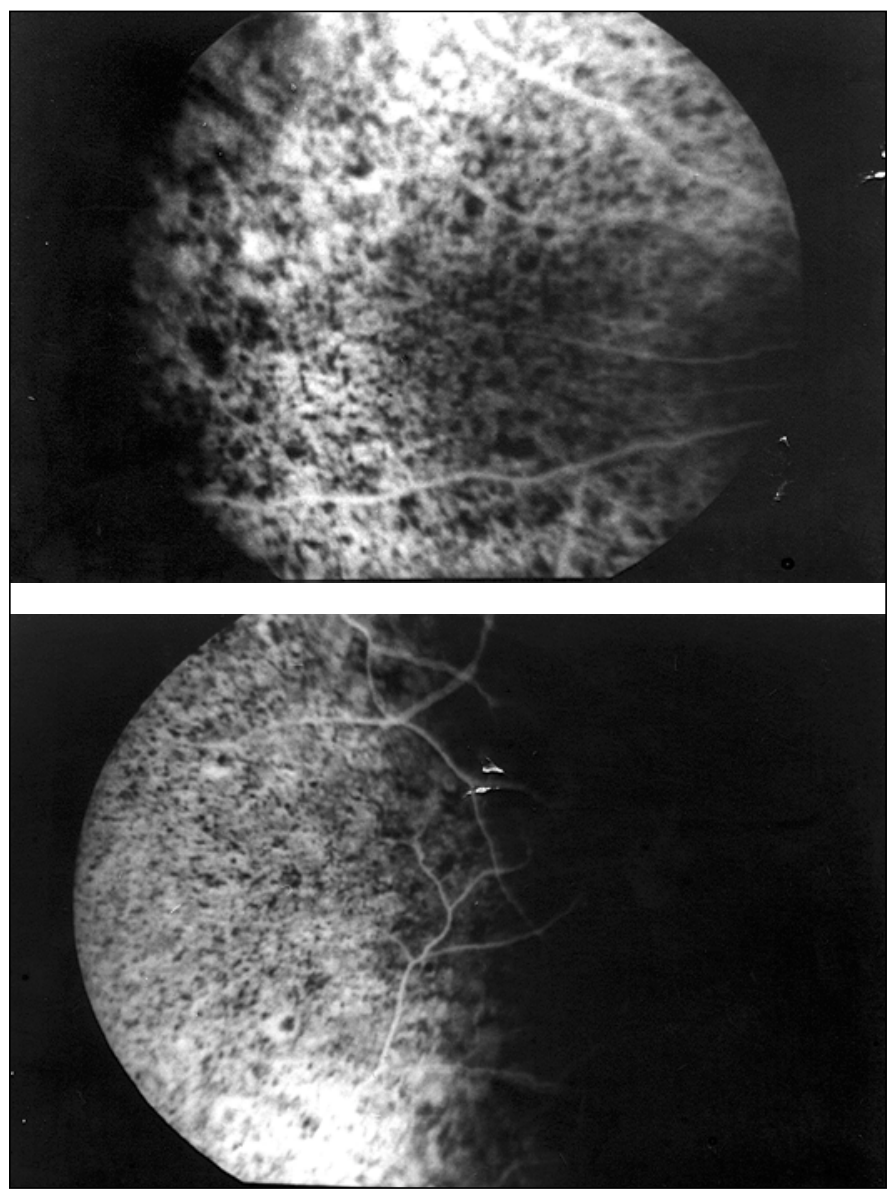

Figuras 3 e 4 - Angiografia da região equatorial

na síndrome da imunodeficiência adquirida (AIDS), essas relacionadas principalmente com contagens de CD4+ abaixo de 200 céls $/ \mathrm{mm}^{3(4)}$. A principal infecção ocular na AIDS é a retinite por citomegalovirus $(\mathrm{CMV})^{(5)}$. As doenças oportunistas apresentam, na grande maioria das vezes, quadros clínicos típicos o que possibilita o diagnóstico apenas por meio de exame oftalmológico. No caso descrito a paciente não apresentava qualquer alteração característica de doença oportunista, além de todos os exames solicitados serem negativos.

Algumas drogas utilizadas no tratamento da AIDS ou de doenças associadas podem causar doença ocular. Cidofovir e rifabutin, drogas para o tratamento de CMV e micobacteriose atípica respectivamente estão associadas a uveíte anterior ${ }^{(6)}$. Nossa paciente não apresentava processo inflamatório no segmento anterior e tampouco fez uso dessas drogas.

Até o momento duas drogas utilizadas no tratamento da AIDS ou doenças associadas estão relacionadas ao comprometimento retiniano. A clofazimina é uma droga utilizada no tratamento da doença de Hansen e em casos de micobacteriose atípica. Cunninghan et al. ${ }^{(7)}$ descreveram um caso de maculopatia tipo bull's eye a qual consideraram ser secundária ao uso de clofazimina. Apesar da suspensão da droga não houve melhora do quadro ocular. Whitcup et al. ${ }^{(2)}$ descreveram um 
caso de criança HIV positiva que apresentou lesões numulares periféricas em ambos os olhos. Os autores justificaram o aparecimento das lesões ao uso de altas doses de DDI. Mais tarde um estudo maior foi realizado onde foram encontradas três crianças com as mesmas lesões periféricas secundárias a altas doses de $\mathrm{DDI}^{(8)}$. Apesar de bem documentadas essas lesões secundárias ao uso da didanosina são bastante raras. Classicamente essas alterações relacionadas ao DDI acometiam apenas crianças que receberam altas doses da droga. Cobo et al. descreveram os primeiros casos de retinopatia associada ao DDI em adultos ${ }^{(3)}$. Em todos os casos descritos na literatura os pacientes apresentaram lesões numulares periféricas em ambos os olhos, assim como descrevemos em nossa paciente. Lalonde et al. ${ }^{(9)}$ descreveram um caso isolado de uveíte anterior e edema macular cistóide associado a zidovudina (AZT). Nossa paciente nunca apresentou alteração macular ou uveíte anterior. A associação de AZT com edema macular foi relatada apenas uma vez, apesar do AZT ser droga de primeira escolha no tratamento da infecção pelo HIV.

Whitcup et al. ${ }^{(10)}$ realizaram estudo anatomo-patológico que demonstrou que as lesões ocorrem primariamente no epitélio pigmentário da retina e acometem posteriormente a coriocapilar. O mecanismo pelo qual o epitélio pigmentário retiniano é lesado devido ao DDI é ainda desconhecido, porém parece estar relacionado ao efeito da droga sobre o DNA mitocondrial.

Este relato demonstra a importância do exame oftalmológico de rotina em pacientes HIV, mesmo quando os pacientes não apresentam risco de doença oportunista ocular.

\section{A B S T RAC T}

The authors report a case of an adult patient infected with the human immunodeficiency virus (HIV) who presented with retinal toxicity due to didanosine. Didanosine is a reverse transcriptase inhibitor used in AIDS treatment. The association of didanosine and retinal toxicity is well established in children although it is very rare in adults.

Keywords: Retinal diseases/etiology; Retinal diseases/ physiopathology; Acquired immunodeficiency syndrome; HIV infection; Didanosine/adverse effects

\section{REFERENCIAS}

1. Lambert JS, Seidlin M, Reichman RC, Plank CS, Laverty M, Morse GD, et al. 2'3' dideoxyinosine (ddi) in patients with the acquired immunodeficiency syndrome or AIDS-related complex: a phase I trial. N Engl J Med 1990;322: 1333-40.

2. Whitcup SM, Butler KM, Pizzo PA, Nussenblatt RB. Retinal lesions in children treated with dideoxyinosine. N Engl J Med 1992;326:1226-7.

3. Cobo J, Ruiz MF, Figueroa MS, Antela A, Quereda C, Perez-Elias MJ, Corral I, Guerrero A. Retinal toxicity associated with didanosine in HIVinfected adults. AIDS 1996;10:1297-300.

4. Jabs DA, Green WR, Fox R, Polk BF, Bartlett JG. Ocular manifestation of acquired immune deficiency syndrome. Ophthalmology 1989;96:1092-9.

5. Kuppermann BD, Petty JG, Richman DD, Mathews WC, Fullerton SC, Rickman LS, Freeman WR. Correlation between CD4+ counts and the prevalence of cytomegalovirus retinitis and human immunodeficiency virusrelated noninfectious retinal vasculopathy in patients with acquired immunodeficiency syndrome. Am J Ophthalmol 1993;155:575-82.

6. Moorthy RS, Valluri S, Jampol LM. Drug induced uveitis. Surv Ophthalmol 1998;42:557-70.

7. Cunninghan CA, Friendberg DN, Carr RE. Clofazamine-induced generalized retinal degeneration. Retina 1990;10:131-4.

8. Whitcup SM, Butler KM, Caruso R, de Smet MD, Rubin B, Husson RN, et al. Retinal toxicity in human immunodeficiency virus-infected children treated with 2'3' dideoxyinosine. Am J Ophthalmol 1992;113:1-7.

9. Lalonde RG, Deschenes JG, Seamone C. Zidovudine-induced macular edema. Ann Intern Med 1991;114:297-8.

10. Whitcup SM, Dastgheib K, Nussenblatt RB, Walton RC, Pizzo PA, Chan CC. A clinicopathologic report of the retinal lesions associated with didanosine. Arch Ophthalmol 1994;112:1594-8.

$$
\begin{aligned}
& \text { Novidades na Internet!!! } \\
& \text { Agora no site } \mathrm{CBO} \text { você tem disponivel todas as informações na integra dos } \\
& \text { Arquivos Brasileiros de Oftalmologia } \\
& \text { fittp://www.c bo,com, } \mathfrak{b r / a b o}
\end{aligned}
$$

